\title{
The Level of Creative Abilities Dimensions According to Torrance Formal Test (B) and Their Relationship with Some Variables (Sex, Age, GPA)
}

\author{
Habis Awamleh ${ }^{1}$, Yacoub Al Farah ${ }^{1} \&$ Ibrahim El-Zraigat $^{2}$ \\ ${ }^{1}$ AL-Balqa' Applied University-Princess Alia University College, Amman, Jordan \\ ${ }^{2}$ Faculty of Education, University of Jordan, Amman, Jordan \\ Correspondence: Yacoub Al Farah, Associate Professor of Special Education, AL-Balqa' Applied University \\ -Princess Alia University College, Fuhais P. O. box (505), Amman 19152, Jordan. E-mail: \\ jacoubfarah@hotmail.com
}

\author{
Received: September 2, 2012 Accepted: September 7, 2012 Online Published: October 12, 2012 \\ doi:10.5539/ies.v5n6p138 URL: http://dx.doi.org/10.5539/ies.v5n6p138
}

\begin{abstract}
This study aimed to identify the level of dimensions for creative abilities (originality, flexibility, originality, elaboration) among students in Al Rai Jordanian schools according to Torrance Formal test, and to investigate the differences in these levels attributable to the study variables (gender, age, grade point average "GPA").

The study sample consisted of (63) students: (31) males (32) females aged six, seven and eight from grades one, two and three attending the mentioned school for the academic year 2010-2011.

The researchers used Torrance formal test form (b), calculated means, standard deviations and ANOVA, and used Schaffe's test for posterior comparisons.

The study indicated that most creative thinking skills (fluency, flexibility, and elaboration) scored a medium level while originality was at a low level, the presence of statistically significant differences in the dimensions of fluency and flexibility attributed to sex in favor of females, and also showed a statistically significant differences between the performance of students means on the Torrance Test due to the variables of age and in favor for (8 and 7) years old over those (6) years old.

In addition, the researchers found statistically significant differences for the means of the sample performance on the test dimensions for the variable GPA in favor for those of GPA (70-85, and 85 and above). All of this clearly indicates the strong relation between the variables of (age, sex, and GPA) and the level of creative abilities dimension respectfully.
\end{abstract}

Keywords: creativity, originality, flexibility, fluency, elaboration

\section{Introduction}

The views of scientists Contrast in defining the concept of creativity idiomatically, as everyone handles this concept from the view of his specialization, scientific background and personal interests. Yet there is a major development in the concept of creativity, through three main phases: the first phase, which lasted since ancient times to the stage of Renaissance, when the concept of creativity in that stage was marked by mixing the concept of creativity with intelligence, talent and early maturity. The second phase, which began with the late nineteenth century, focused on the role of genetics in creativity, and the American School which focused on highlighting the role of social and environmental factors. it was also characterized by the emergence of the psychological theory which attempted to explain creativity, also appeared to the stage equality between the concepts of creativity geniuses and intelligence, with receding controversy on the impact of genetics and environment, in the creative process as well as the development of some creativity measure tools and programs to develop and teach creativity. At The third phase, the concept of creativity became more apparent at this stage that reached from the mid-twentieth century until the present day.

The creativity tests do not have complete aspects nor are ideal, and the results may be misleading sometimes, as a student maybe creative in a subject such as science or arts, but scores average degree in creativity tests. Also, the validity coefficients to creativity tests between the test results with another criterion of creativity as teacher 
evaluation for example, or performance evaluations and creative products, may range between $25-40 \%$ and this is not high enough, as creativity is a complex and compound ability that can take endless forms, as indicated Davis (1989) that is impossible to measure creative ability in a very precise way. (Davis, 1989).

The educator Torrance is at the forefront of scientists who popularized and published tests of creative thinking or what is called Torrance Test of Creative Thinking (TTCT). These include verbal and non-verbal subtests, and are established to measure verbal and flexibility fluency; which means (the number of ideas that arise to solve a particular problem, and there are intellectual discrimination, originality and elaboration, by which we mean (the number of additional and new non-traditional elaboration. Torrance \& Ball (1948) innovated a simplified system for scoring points in digital tests, and there are other tests for creative thinking established by Guilford (1977), Williams (1980) Wallach and Kogan (1965) Jitzil and Jackson, and Torrance tests for pre-school children (1982).

\section{Literature Review}

Runco study in (1993) aimed to investigate the effect of sex on creative thinking, the study sample consisted of (607) students from grades four and six, on whom he applied Torrance formal Test of Creative Thinking. The study results indicated the absence of statistically significant differences for creative thinking between the two sexes.

Rossa (1996) study aimed to investigate the effectiveness of three strategies for the development of creative thinking skills among gifted students in the second and third grades. The results showed an improvement in creative thinking skills, verbal and formal on the study sample, and results showed the presence of improvement in the creative thinking skills, both formal and verbal, among students by $80 \%$ and this indicates the effectiveness of the program in the development of creative thinking skills, and the strength of the test in the detection of strengths and improvement in creative thinking.

Ceci \& Loftus (1994) study aimed at investigating the importance of imagination in the development of creative thinking skills (fluency, flexibility, originality). The researchers used Torrance formal Test of Creative Thinking, and results showed that there were statistically significant differences between the experimental group and the control group in favor for the experimental group in creative thinking, and also showed differences in fluency and flexibility in favor of females on the Torrance Test of Creativity.

Alexander \&Patricia study (1994) aimed to determine the impact of fairy and realism tales on creative solutions to the sample of (100) child of kindergarten through second grade, Creative solutions to Torrance test. The results of the study indicated that children's achievements related to creative solutions have increased with increasing age and experience.

Walberg conducted a series of studies on excelling children in the years 1982.1988, 1994, and continued his research with Zeiser on common characteristics of children with creative thinking in the United States. They concluded that $80 \%$ of children with creative thinking scored high in academic excellence, great love for the school and had superior communication skills. (Walberg \& Zeiser, 1997).

\section{The Problem and Importance of the Study}

Creativity is one the most important educational goals that developed human societies seek to achieve, as creative individuals play an important and effective role in the development of their communities in educational, social and artistic areas. Societies today desperately need to pay attention to creative students, who on whom they build hope in the progress and development of our societies, what neediest of our students to develop creative and cognitive aspects in order to output energies of their creativity and channel them in the right direction.

By working in the field of creativity, especially in schools that deal with attention to and developing creativity among students, we find that most of the creative students suffer greatly from the lack of knowledge about the means of detecting their creative abilities accurately, and learning aspects of the strengths and weaknesses in the area of talent and creativity.

Therefore, it is necessary to identify the ability of Torrance formal Test to identify how accurate it is in diagnosing these creative abilities, learning its applications, analyzing its results to establish a good, appropriate and important tool to everyone who works in this area, whether they are teachers, experts or detectors of creative ability. Hence the problem with this study is determined by the answer to the main question:

"What is the level of creativity (originality, flexibility, originality, elaboration) at the students in Al Rai Jordanian schools according to Torrance formal test? 


\section{Research Questions}

1) Does the level of creative abilities of students in Al Rai Jordanian schools Vary according Torrance formal test attributing to sex?

2) Does the level of creative abilities of students in Al Rai Jordanian schools Vary according Torrance formal test attributing to age?

3) Does the level of creative abilities of students in Al Rai Jordanian schools Vary according Torrance formal test attributing to GPA?

\section{The Objectives of the Study}

The objective of the study is to detect the level creative abilities (originality, flexibility, originality, elaboration) among the students Al Rai Jordanian Schools according to Torrance formal test attributing to different variables (sex, age, grade point average). Also, the aim of this study is to identify the creative abilities of students who do not attend talent and creativity schools in Jordan, and whether they differ in creative abilities from others at other schools that are designed for, focused on and dedicated to gifted education.

This kind of schools is the base for raising the next generation and upbringing them rightfully, as such schools are popular and major in the Ministry of Education. In addition to identifying the ability of conventional schools in the development of creativity, compared with other schools dealing with the talented and creative people.

\section{Terms of the Study}

Creative abilities: Torrance (1971) identified creative abilities as cognitive processes of the problems, gaps, changes or inconsistencies in the knowledge associated with the field of areas that are highly valued by the group, and these abilities are fluency, flexibility, and originality, in addition to elaboration.

Creativity: Santrock identified creativity as the ability to think about a subject in different unusual ways and reaching unique solutions to the problems. (Awamleh et al, 2008).

Al Rai Jordanian Schools: one private school for ordinary students reporting to the Ministry of Education in the province of Amman.

Torrance Test of Creative Thinking: a test prepared Torrance in the year (1962) and is concerned in testing creative thinking, referred to as (TTCT). In (1974) it was revised so it could identify students' creative abilities, and later in (1992) it was further revised. It is considered one of the most popular international creativity tests.

\section{Research Methodology}

7.1 The Study Sample

Table (1). Study Sample distribution

\begin{tabular}{llll}
\hline variable & Category & count & percentage \\
\hline \multirow{4}{*}{ Sex } & Male & 31 & 49.2 \\
& Female & 32 & 50.8 \\
& Total & 63 & 100 \\
\multirow{4}{*}{ Age } & 6 & 20 & 31.7 \\
& 7 & 17 & 27.0 \\
& 8 & 26 & 41.3 \\
& Total & 63 & 100 \\
GPA & Less than 69 & 11 & 17.5 \\
& 70 -less than 85 & 32 & 50.8 \\
& 85 and more & 20 & 31.7 \\
& Total & 63 & 100 \\
\hline
\end{tabular}


The study sample consisted of all students aged 6,7 and 8 Al Rai Jordanian schools mounting (63) students of whom (31) males and (32) females. Aged six were (20), aged seven were (17) and aged eight were (26) students in the age of the eighth year. They were enrolled at the mentioned school in Amman for the academic year 2010/2011. Table (1) shows the distribution of the study sample.

\subsection{The Study Tool}

Torrance Test of Creative Thinking (Formal Test form (B) was used. and this tests is one of the most tools used to measure the creative abilities which are (originality, flexibility, fluency, elaboration). They consist of two parts: verbal language-dependent tests, and shapes tests that depend on the formation of shapes and images, and each part has two forms (a) and (b).

These tests measure creative thinking abilities in an age range extending from kindergarten to postgraduate studies, and can be applied individually or collectively. The researchers used Torrance formal test, form (b), which was adapted to suit the Arab environment by Suleiman and Abu Hatab in (1988). The test used in the current study consists of three activities: the first activity (image formation), the second activity (completion of lines) and the third activity (circles). The given time is ten minutes per activity and thus the total test time is (30) minutes.

\subsection{The Validity and Reliability of the Tool}

This test is Characterized by a high degree of validity (concept convergent, predictive), and the reliability of correctors was no less than (0.95). Also, the coefficient for test reliability by reapplication of the test was $(0.60)$ for the originality, $(76 \%)$ for flexibility, $(69 \%)$ for fluency and $(73 \%)$ for elaboration. (Suleiman, Abu Hatab, 1988).

The Researchers adopted the study tool after being validated through the observations of specialists, then the final form of the tool was used. Next the tool was applied on a pilot Sample of (10) members from outside the study sample, in order to verify the validity of the tool by (Test- R-test) technique, and with a period of two weeks between the first and second application. Then reliability coefficient was calculated for internal consistency and was $(0.81 \%)$, and this percentage is considered good and statistically acceptable for the purposes of this study.

\subsection{The Statistical Treatment}

Means, Standard Deviations and T-Test were used here. Also, Schaffe's Test for posterior comparison of students' performance means and one way ANOVA were used.

\section{The Study Findings}

This section will display the search results that have been reached according to the study questions.

Regarding the first question about the level of the creative abilities dimensions of the study sample according to Torrance formal Test (b), means and standard deviations for the performance of the study sample on every dimension of Torrance formal test were calculated and Table (2) shows that:

Table (2). Means and standard deviations for the performance of the study sample on every dimension of Torrance formal test

\begin{tabular}{llll}
\hline Dimension & Mean & Standard Deviation & Level \\
\hline Fluency & 34.6 & 5.3 & Medium \\
Flexibility & 17.0 & 3.8 & Medium \\
Originality & 6.7 & 1.8 & Low \\
elaboration & 45.7 & 10.6 & medium \\
\hline
\end{tabular}

Table (2) shows that the dimensions (fluency, flexibility, and elaboration) scored with a medium level, as elaboration was the highest level with a mean (45.7) and a standard deviation (10.6), followed by fluency a mean of (34.6) and standard deviation (5.3), the flexibility obtained after arithmetic average (17.0) with a standard deviation (3.8) and finally originality scored a mean of (6.7) and a standard deviation (1.8), which was very low. 
Regarding the second question about the level of the creative capacities dimensions of the study sample variance according Torrance formal test according to sex, we calculated means, standard deviations and (t-test) for the performance of the study sample on every dimension of test according to the variable (sex). Table (3) shows that:

Table (3). Means, standard deviations and (t-test) for the performance of the study sample on every dimension of test according to the variable (sex)

\begin{tabular}{llllllll}
\hline Dimension & sex & count & mean & SD & $\begin{array}{l}\text { T } \\
\text { Value }\end{array}$ & $\begin{array}{l}\text { Degree of } \\
\text { Freedom }\end{array}$ & $\begin{array}{l}\text { Statistical } \\
\text { significance }\end{array}$ \\
\hline Fluency & Male & 31 & 32.06 & 4.41 & 4.173 & 61 & $* 0.000$ \\
& Female & 32 & 37.0 & 4.95 & & & $* 0.044$ \\
Flexibility & Male & 31 & 15.97 & 4.05 & 2.061 & 61 & \\
& Female & 32 & 17.91 & 3.40 & & & $* 203$ \\
Originality & Male & 31 & 6.45 & 1.80 & 1.288 & 61 & \\
& Female & 32 & 7.03 & 1.77 & & & \\
& Male & 31 & 46.32 & 10.79 & 0.434 & 61 & \\
& Female & 32 & 45.16 & 10.56 & & & \\
\hline
\end{tabular}

* Statistically significant at $(\alpha=0.05)$

Table (3) shows the presence of a statistically significant difference at the level of statistical significance $(\alpha=$ 0.05 ) between the two means of the study sample), where males got a in fluency a mean of (32.06) standard deviation (4.41) and the value of $\mathrm{T}$ was (4.173), while in the same dimension females mean was (37.00) standard deviation (4.95). Inflexibility males scored a mean of (15.97) standard deviation (4.05) and the value of $\mathrm{T}$ was (2.061), while in the same dimension females mean was (17.91) and standard deviation was (3.40). It is worth mentioning that females' performance didn't have any statistical significance and thus there $\mathrm{T}$ test values were not mentioned.

Regarding the third question about the level of the creative capacities dimensions of the study sample variance according Torrance formal test according to age, we calculated means and standard deviations for the performance of the study sample on every dimension of test according to the variable (age), and table (4) shows that.

Table (4). Means and standard deviations for the performance of the study sample on every dimension of test according to the variable (age)

\begin{tabular}{lllll}
\hline Dimension & Age & Count & Mean & SD \\
\hline Fluency & 6 & 20 & 32.85 & 5.63 \\
& 7 & 17 & 34.47 & 5.01 \\
Flexibility & 8 & 26 & 35.96 & 4.95 \\
& 6 & 20 & 16.15 & 4.27 \\
& 7 & 17 & 16.76 & 4.48 \\
Originality & 8 & 26 & 17.69 & 2.92 \\
& 6 & 20 & 6.20 & 2.02 \\
& 7 & 17 & 6.76 & 1.64 \\
Elaboration & 8 & 26 & 7.15 & 1.67 \\
& 6 & 20 & 40.00 & 11.80 \\
& 7 & 17 & 47.59 & 7.38 \\
& 8 & 26 & 48.92 & 9.95 \\
\hline
\end{tabular}


Table (4) show that There are apparent differences between the means for the performance of study sample on the dimensions of the test regarding the level of creative abilities and according to Torrance formal test among students in the study sample and according to the variable (age). On order to identify learn the statistical significance of these differences; the researchers used One Way ANOVA), and table (5) shows that.

Table (5). ANOVA results for means for the performance of students (study sample) on the test dimensions according to (age)

\begin{tabular}{|c|c|c|c|c|c|c|}
\hline Dimension & $\begin{array}{l}\text { Source of } \\
\text { variance }\end{array}$ & $\begin{array}{l}\text { Sum } \\
\text { squares }\end{array}$ & $\begin{array}{ll}\text { Degree } & \text { of } \\
\text { Freedom } & \end{array}$ & $\begin{array}{l}\text { Sum of } \\
\text { squares }\end{array}$ & $\begin{array}{l}\text { F } \\
\text { value }\end{array}$ & $\begin{array}{l}\text { Statistical } \\
\text { significance }\end{array}$ \\
\hline & Among groups & 109.682 & 2 & 54.841 & 2.034 & 0140 \\
\hline \multirow[t]{3}{*}{ Fluency } & Inside groups & 1.617 .747 & 60 & 26.962 & & \\
\hline & Total & 1.727 .429 & 62 & & & \\
\hline & Among groups & 27.710 & 2 & 13.855 & 0.943 & 0.395 \\
\hline \multirow[t]{3}{*}{ Flexibility } & Inside groups & 881.147 & 60 & 14.686 & & \\
\hline & Total & 908.857 & 62 & & 1.628 & \\
\hline & Among groups & 10.293 & 2 & 5.147 & & 0.205 \\
\hline \multirow[t]{3}{*}{ Originality } & Inside groups & 189.643 & 60 & 3.161 & 4.910 & \\
\hline & Total & 199.937 & 62 & & & \\
\hline & Among groups & 980.449 & 2 & 490.224 & & $* 0.011$ \\
\hline \multirow[t]{2}{*}{ Elaboration } & Inside groups & 5.989 .964 & 60 & 99.833 & & \\
\hline & Total & 6.970 .413 & 62 & & & \\
\hline
\end{tabular}

Table (5) sows that there were statistically significant differences at the level of statistical significance $(\alpha=0.05)$ between the mean of the performance of students (study sample) regarding the dimension of elaboration, according Torrance formal test among according to the variable (age). In order to identify to whose favor the differences are, Schaffe's test for posterior comparison was used, and the table (6) shows that.

Table (6). Schaffe's Test of Posterior Comparisons for the sample students' performance on Elaboration and according to age

\begin{tabular}{llll}
\hline & & 7 & 8 \\
\hline Age & Mean & 47.59 & 48.92 \\
6 & 40.00 & $* 7.59$ & $* 8.92$ \\
7 & 47.59 & & 1.33 \\
8 & 48.92 & & \\
\hline
\end{tabular}

* Statistically significant at $(\alpha=0.05)$

Evident from table (6) that the students with age (6) years got a mean of (40.00) and level of significance (1.33), while age (7) years got a mean of (47.59) and level of significance (7.59) and finally Age (8) years mean was (48.92) and the level of significance (8.92).

Table (6) shows and there were statistically significant differences at the level of statistical significance $(\alpha=0.05)$ between the means of students performance (study sample) with age (7 and8) on the one hand and with age (6) of the other hand and in favor of all of those aged ( 7 and 8 ) years.

Regarding the fourth question about the level of the creative capacities dimensions of the study sample variance according Torrance formal test according to GPA, the researchers calculated means and standard deviations for the performance of the study sample on every dimension of test according to the variable (GPA), and Table (7) shows that. 
Table (7). Means and standard deviations for the performance of the study sample on the test dimensions according to the variable of GPA

\begin{tabular}{lllll}
\hline Dimension & GPA & Count & Mean & SD \\
\hline \multirow{3}{*}{ Fluency } & 69 and less & 11 & 34.18 & 5.65 \\
& 70-less than 85 & 32 & 32.50 & 4.17 \\
Flexibility & 85 and above & 20 & 38.10 & 4.84 \\
& 69 and less & 11 & 16.91 & 4.46 \\
& 70 -less than 85 & 32 & 15.78 & 3.95 \\
Originality & 85 and above & 20 & 18.85 & 2.23 \\
& 69 and less & 11 & 6.82 & 1.99 \\
& 70 -less than 85 & 32 & 6.06 & 1.52 \\
Elaboration & 85 and above & 20 & 7.80 & 1.64 \\
& 69 and less & 11 & 39.36 & 10.52 \\
& 70 -less than 85 & 32 & 47.59 & 9.72 \\
\hline
\end{tabular}

Table (7) shows the existence of apparent differences between the means for the performance of students (study sample) on the dimensions of the test relating to the level of creative abilities and according to Torrance formal test according to the variable of (GPA). As elaboration was the highest mean within the category of GPA (70-85), as the mean was (47.59) and standard deviation (9.72), followed by GPA (85 and above), where the mean was (46.25) and standard deviation (11.17), as well as GPA (69 and below) got the mean (39.36) and standard deviation (10.52). Then dimensions descended until they reached the least level which is originality, where GPA (85 and more) had a mean of (7.80) and Standard Deviation, (1.64) and descended further gradually until it reached GPA (70-85) where the mean was (6.06) and standard deviation (1.52). To find out the statistical significance of these differences; One Way ANOVA was used, and the table (8) shows that.

Table (8). ANOVA results for the study sample performance on the test dimensions according to GPA

\begin{tabular}{|c|c|c|c|c|c|c|}
\hline Dimension & $\begin{array}{ll}\text { Source } \\
\text { variance }\end{array}$ & $\begin{array}{l}\text { Sum } \\
\text { squares }\end{array}$ & $\begin{array}{l}\text { Degree of } \\
\text { Freedom }\end{array}$ & $\begin{array}{l}\text { Sum of } \\
\text { squares }\end{array}$ & $\begin{array}{l}\text { F } \\
\text { value }\end{array}$ & $\begin{array}{l}\text { Statistical } \\
\text { significance }\end{array}$ \\
\hline & Among groups & 387.992 & 2 & 193.996 & 8.690 & $* 0.000$ \\
\hline \multirow[t]{3}{*}{ Fluency } & Inside groups & 1.339 .436 & 60 & 22.324 & & \\
\hline & Total & 1.727 .429 & 62 & & & \\
\hline & Among groups & 115.929 & 2 & 57.965 & 4.386 & $* 0.017$ \\
\hline \multirow[t]{3}{*}{ Flexibility } & Inside groups & 792.928 & 60 & 13.215 & & \\
\hline & Total & 908.857 & 62 & & & \\
\hline & Among groups & 37.225 & 2 & 18.613 & 6.863 & $* 0.002$ \\
\hline \multirow[t]{3}{*}{ Originality } & Inside groups & 162.711 & 60 & 2.712 & & \\
\hline & Total & 199.937 & 62 & & & \\
\hline & Among groups & 562.398 & 2 & 281.199 & 2.633 & 0.080 \\
\hline \multirow[t]{2}{*}{ Elaboration } & Inside groups & 6.408 .014 & 60 & 106.800 & & \\
\hline & Total & 6.970 .413 & 62 & & & \\
\hline
\end{tabular}

* Statistically significant at $(\alpha=0.05)$

Table (8) shows that there were statistically significant differences at the level of statistical significance $(\alpha=0.05)$ between the mean of the performance of students (study sample) on all dimensions according to Torrance formal 
test attributed to the variable (GPA), and in order to find out to whose favor these differences, Schaffe's test for posterior comparisons was used, and table (9) shows this.

Table (9). Schaffe's posterior comparisons to the impact of the GPA variable on the dimensions of fluency, flexibility and originality

\begin{tabular}{|c|c|c|c|c|c|}
\hline Dimension & Category & Mean & 69 and less & $\begin{array}{l}\text { 70- less than } \\
85\end{array}$ & $\begin{array}{l}85 \text { and } \\
\text { above }\end{array}$ \\
\hline & 69 and less & 34.18 & & & \\
\hline \multirow[t]{3}{*}{ Fluency } & 70 - less than 85 & 32.50 & 1.68 & & \\
\hline & 85 and above & 38.10 & $* 3.92$ & $* 5.6$ & \\
\hline & 69 and less & 16.91 & & & \\
\hline \multirow[t]{3}{*}{ Flexibility } & 70 - less than 85 & 15.78 & 1.13 & & \\
\hline & 85 and above & 18.85 & 1.94 & $* 3.07$ & \\
\hline & 69 and less & 6.82 & & & \\
\hline \multirow[t]{2}{*}{ Originality } & 70 - less than 85 & 6.06 & 0.76 & & \\
\hline & 85 and above & 7.80 & 0.98 & $* 1.74$ & \\
\hline
\end{tabular}

* Statistically significant at $(\alpha=0.05)$

Table (9) show that there are statistically significant differences at the level of statistical significance $(\alpha=0.05)$ among those with GPA of 85 or higher on the one hand and both with GPA of 69 or less and $70-$ less than 85 on the other hand, in favor for GPA 85 or higher in fluency dimension.

The results also showed statistically significant differences at the level $(\alpha=0.05)$ among those with the GPA of 85 or higher and whose GPA is 70 - less than 85 , and for the favor of people with GPA 85 or higher in the dimensions of flexibility and originality.

\section{Results and Discussion}

The Results of the study indicated that creative thinking (fluency, flexibility, and elaboration) came with a medium level, while originality was at a level low. it also found that there are statistically significant differences in fluency and flexibility attributed to sex (for females), and showed the presence of statistically significant differences between the means of students performance on Torrance Test due to the variable of age and for the benefit of the category ( 7 and 8 ) years old. Finally the results showed statistically significant differences in the performance of the sample means on the dimensions of the test regarding the variable GPA, as they came in favor for students with average (70-85, 85 and above). In the following I will review these results in detail:

The results of the main question about the level of the dimensions of the creative abilities of the students study sample according to Torrance formal test form (b) suggest that most of the dimensions of the test (fluency, flexibility, elaboration) were at a medium level while only originality dimension was at a low level.

The means descended, as in elaboration it was (45.7) then originality had it (6.7). this result may agree with most of what came from previous studies that focused on the effectiveness of giving programs for the development of creative thinking to reach female students to creative thinking skills, as agreed with the findings of the study by Rossa (1996), which indicated the effectiveness of programs that are given to students in the development of creative thinking. In addition the results of this study show that the study sample are individuals in a regular school that does not cater for development programs for creative thinking, so findings come expressive of the modest level of interest in these programs in regular schools compared to talented schools.

Regarding the second question about the level of the creative capacities dimensions of the study sample variance according Torrance formal test according to sex, The results of the study show that there were statistically significant differences at the significance level of $(A=0.05)$ between student performance means on the dimensions fluency and flexibility attributed to gender in favor for females and this result is consistent with the findings of the study results by Ceci \& Loftus (1994), which indicated the presence of statistically significant differences in fluency and flexibility in favor for females at the expense of male Torrance formal Test of Creativity. However the findings are not consistent with the study by Runco (1993), which indicated that there 
were no statistically significant differences due to gender, and the result may be (according to the researchers) expressive of speedy language development in girls compared to male children, especially in the first ages of a child's life, and this activates the ability of fluency and flexibility larger in girls compared to boys.

regarding the second question about the level of the creative capacities dimensions of the study sample variance according Torrance formal test according to age The results showed that there were apparent differences between performance of students means on the dimensions of the test according to the variable (age) level of the student, and to identify the significance of these differences ANOVA was used and the results showed the existence of significant differences due to the variable of age as the value of $\mathrm{P}$ was (4.910) and statistically significant (0.011) in favor with ages (7 and 8) years of hand and with age (6) years on the other hand. This result agreed with the findings of the study by Alexander \& Patricia (1994), which indicated that achievements of children relating to creative solutions increased with increasing age and experience.

regarding the second question about the level of the creative capacities dimensions of the study sample variance according Torrance formal test according to GPA The results showed apparent differences between the mean of students performance on the dimensions of the test according to the variable GPA. To identify these differences ANOVA was used, and to identify for whose favor they are, Schaffe's test for posterior comparisons was also used. Finally the study results showed there were statistically significant differences at the level of $(A=0.05)$ in means of performance in favor for those with GPA ( 85 or higher) on the one hand, and both with GPA (69 or less) and (70 - less than 85) or higher in fluency dimension.

The results also showed the existence of differences between people with GPA of 85 or higher and whose GPA is 70 - less than 85 , in favor for those students with average 85 or higher in the dimensions of flexibility and originality. The results of the main question about the level of the dimensions of the creative abilities of the students study sample according to Torrance formal test form (b) suggest that most of the dimensions of the test (fluency, flexibility, elaboration) were at a medium level while only originality dimension was at a low level.

The means descended, as in elaboration it was (45.7) then originality had it (6.7). this result may agree with most of what came from previous studies that focused on the effectiveness of giving programs for the development of creative thinking to reach female students to creative thinking skills, as agreed with the findings of the study by Rossa (1996), which indicated the effectiveness of programs that are given to students in the development of creative thinking. In addition the results of this study show that the study sample are individuals in a regular school that does not cater for development programs for creative thinking, so findings come expressive of the modest level of interest in these programs in regular schools compared to talented schools.

Regarding the second question about the level of the creative capacities dimensions of the study sample variance according Torrance formal test according to sex, The results of the study show that there were statistically significant differences at the significance level of $(\mathrm{A}=0.05)$ between student performance means on the dimensions fluency and flexibility attributed to gender in favor for females and this result is consistent with the findings of the study results by Ceci \& Loftus (1994), which indicated the presence of statistically significant differences in fluency and flexibility in favor for females at the expense of male Torrance formal Test of Creativity. However the findings are not consistent with the study by Runco (1993), which indicated that there were no statistically significant differences due to gender, and the result may be (according to the researchers) expressive of speedy language development in girls compared to male children, especially in the first ages of a child's life, and this activates the ability of fluency and flexibility larger in girls compared to boys.

regarding the second question about the level of the creative capacities dimensions of the study sample variance according Torrance formal test according to age The results showed that there were apparent differences between performance of students means on the dimensions of the test according to the variable (age) level of the student, and to identify the significance of these differences ANOVA was used and the results showed the existence of significant differences due to the variable of age as the value of $\mathrm{P}$ was (4.910) and statistically significant (0.011) in favor with ages (7 and 8) years of hand and with age (6) years on the other hand. This result agreed with the findings of the study by Alexander \& Patricia (1994), which indicated that achievements of children relating to creative solutions increased with increasing age and experience.

regarding the second question about the level of the creative capacities dimensions of the study sample variance according Torrance formal test according to GPA The results showed apparent differences between the mean of students performance on the dimensions of the test according to the variable GPA. To identify these differences ANOVA was used, and to identify for whose favor they are, Schaffe's test for posterior comparisons was also used. Finally the study results showed there were statistically significant differences at the level of $(A=0.05)$ in 
means of performance in favor for those with GPA ( 85 or higher) on the one hand, and both with GPA (69 or less) and (70 - less than 85) or higher in fluency dimension.

The results also showed the existence of differences between people with GPA of 85 or higher and whose GPA is 70 - less than 85 , in favor for those students with average 85 or higher in the dimensions of flexibility and originality.

\section{Suggestions and Recommendations}

After this study, The Researchers recommend allocating training programs for the development of creative thinking among ordinary and talented students, as well as the recommendation not to deprive ordinary students from training, and inform them of the creative thinking skills and trying to develop these at an early age, as well as refining them to suit the needs of the community, not for such programs not to be limited to schools that deal with gifted students. Furthermore, the researchers recommend conducting further studies on this topic in other schools in the poorer provinces that cater more for ordinary students to find out the level of students' creative abilities in remote places from the capital city of Amman.

\section{References}

Abidin, S. A. (2009). The Effectiveness of a Training Program based on Brainstorming Strategies, Imagination and Redundancy in the Development of Creative Thinking. A study presented at the Sixth Arab Scientific Conference for Gifted and Talented, Amman, Jordan.

Al-Bishawi, A. S. (2008). The Effectiveness of a Training Program based On C.O.R.T Strategies in the Development of Creative Thinking among Students of the third age, unpublished master Thesis, AL-Balqa Applied University, Amman.

Alexander, Patricia. (1994). Young children's creative solutions to realistic and fanciful story problems, Journal of Creative behavior, 28(1), 89-106.

Awamleh, H., \& Rimawi, S. (2008). Fluency among Creative Characteristics According to Renzulli scale, and the Social and Family problems of Talented students from the age of nine, Journal of Qualitative Education, Mansoura University, $12^{\text {th }}$ ed. - July (2008).

Ceci \& Loftus. (1994). Repeatedly thinking about anon-event: Source misattribution among preschoolers. Consciousness and Cognition, 11(3), 380-407.

Davis. S. J., \& Johns, J. (1989). Students as authors: Helping gifted students get published, fifth ed. Child Today, 12(6), 20-22.

Gary A. Davis., \& Syliva B. Rimm. (1998). Education of the Gifted and Talented, Fourth Edition by Gray A, Davis Copy right, 1998, All Rights Reserved.

Huthaili, N. S. (2005). The Effectiveness of a Training Program based on Play in the Development of Innovative Thinking, unpublished master Thesis, University of Jordan, Amman - Jordan.

Jarwan, F. (2002). Creativity: Concept, Standards, Theories, Measurement, Training, and Stages of the Creative Process, Oman -Dar Al Fikr for publication and distribution.

Kunkel. M. A, Chapa, B, Patterson. G., \& Walling, D. (1995). The experience of Giftedness: A concept map. Gifted Child Quarterly. 39, 126-134. http://dx.doi.org/10.1177/001698629503900302

Rossa, P. 1. E. (1996). Teaching young children to think: The effects of a specific Instructional Program. Education the Comet Encyclopedia.

Runco, M. A. (1993). Divergent thinking, Creativity, and giftedness. Gifted Child Quarterly, 37, 16-22.

Suleiman, A., \& Abu Hatab, F. (1988). Creative Thinking Tests using Images (a, b), Cairo - Anglo library.

Torrance, E. P., \& Ball, O. E. (1984). Torrance test of Creative thinking: streamlined (revised) manual Figural A and B. Bensenville, 11: Scholastic Testing Service.

Torrance, E. P. (1971). Are the Torrance tests of Creative thinking biased against or in favor of disadvantaged groups? Gifted child quarterly, 15, 75-81.

Walberg. H.J., \& Zeiser, S. (1997). Productivity, accomifest in its testing. In R. J. Sternberg (Ed), The nature of creativity (pp. 43-75). New York: Cambridge University press. 


\section{Authors}

Habis Suleiman Awamleh, Associate Professor, AL-Balqa' Applied University- Princess Alia University College, Jordan. Ain Al-Basha, P.O. box (42), Zip Code 19374. E-mail: habisawamleh@yahoo.com

Yacoub Fareed Al Farah, Associate Professor of Special Education, AL-Balqa' Applied University -Princess Alia University College, Jordan - Fuhais P.O. box (505), Zip Code 19152. E-mail: jacoubfarah@hotmail.com

Ibrahim El-Zraigat, Associate Professor of Special Education, University of Jordan, Amman, Jordan. E-mail: ibrahimz@ju.edu.jo 